\title{
Cuidados paliativos sob a ótica de familiares de pacientes com neoplasia de pulmão
}

Maria Edilania Matos Ferreira Furtado(a) Darla Moreira Carneiro Leite ${ }^{(b)}$

Furtado MEMF, Leite DMC. Palliative care seen from the point of view of the lung cancer patients' families. Interface (Botucatu). 2017; 21(63):969-80.

The palliative care defend the use of relief therapy for patients suffering in case of life-threatening diseases, respecting their physical, mental, social and spiritual aspects. In this regard, it is intended to identify what the patients' families understand about the relief therapy. This is an exploratory and qualitative study developed by the application of 11 semi-structured interviews with family caregivers. The data emerging from the interviews were subject to content analysis and integrated to the current literature on palliative care. Understandings of palliative care involves from the ignorance of the term to the notion of care of the disease. It is concluded that communication between team-families is essential in the construction of this understanding. Even most families do not acknowledge this fact, the results show a positive setting towards the implementation of the philosophy of palliative care.

Keywords: Palliative care. Family. Lung cancer. Communication.
Os cuidados paliativos defendem o emprego de terapêuticas de alívio do sofrimento de pacientes com doenças ameaçadoras da vida, respeitando suas dimensões física, psíquica, social e espiritual. Neste sentido, buscou-se apreender o que os familiares de pacientes com neoplasia de pulmão entendem por essa terapêutica. Trata-se de estudo qualitativo de cunho exploratório, no qual foram realizadas 11 entrevistas semiestruturadas com familiares cuidadores. Os dados obtidos foram submetidos à análise de conteúdo e articulados à literatura sobre cuidados paliativos. A compreensão dos cuidados paliativos vai desde o desconhecimento do termo à noção de cuidados com a doença. Conclui-se que a comunicação equipe-família é essencial na construção dessa compreensão e que, mesmo não havendo reconhecimento do termo pela maior parte dos familiares, os resultados mostram que o cenário da pesquisa é propício à implantação da filosofia dos cuidados paliativos.

Palavras-chave: Cuidados paliativos. Família. Neoplasias pulmonares. Comunicação. (a) Programa de Residência Integrada em Saúde, Escola de Saúde Pública do Ceará (ESP/CE). Av Antonio Justa, 3161, Meireles. Fortaleza, CE, Brasil. 60165-090. edilaniafurtado@ gmail.com

(b) Hospital de Messejana Dr. Carlos Alberto Studart Gomes. Fortaleza, CE, Brasil. darlamoreiracl@ gmail.com 


\section{Introdução}

Dentre as doenças crônicas não transmissíveis, o câncer tem grande incidência nas estatísticas de morbimortalidade apresentadas pelo mundo. As estatísticas no Brasil, para 2016/2017, apontam 28.220 novos casos dessa patologia, sendo 17.330 para homens e 10.890 para mulheres ${ }^{1}$.

Apesar dos avanços tecnológicos, o câncer de pulmão nem sempre é diagnosticado precocemente, o que compromete a sobrevida do seu portador. Assim, diante da impossibilidade de tratamento curativo, resta a abordagem paliativa², que visa ao alívio da dor e do sofrimento, por privilegiar a prestação do cuidado ao paciente e a sua família ${ }^{3-5}$.

Em se tratando de família e adoecimento, muitas questões compõem a travessia que vai do diagnóstico ao luto vivenciado pela morte, o que requer cuidados para além de procedimentos técnicos. Requer, sobretudo, uma escuta sensível, como fator imprescindível a uma comunicação de qualidade $\mathrm{e}^{6-8}$.

Assim, pensando nos conteúdos dessa comunicação e nos sentidos que produzem, é pertinente questionar-se: Que compreensão têm os familiares de pacientes com neoplasia de pulmão acerca dos cuidados paliativos?

A presente pesquisa tem como objetivo geral compreender os sentidos do termo Cuidados Paliativos para os familiares de pacientes com neoplasia de pulmão e, como objetivos específicos, apreender os sentidos dos cuidados paliativos e discutir a repercussão da comunicação equipe/família na construção desses sentidos.

A relevância desta pesquisa reside no fato de as neoplasias se apresentarem enquanto segunda causa de morte por doenças no Brasil, bem como no aumento expressivo da incidência do câncer a cada ano ${ }^{1,9}$. Isso implica o aumento do número de pessoas que obedecem aos critérios estabelecidos para o recebimento de cuidados paliativos e de familiares cuidadores em contato com esse tema.

A pesquisa contribui ainda para a produção literária sobre o tema, posto que na busca por estudos que subsidiassem sua fundamentação teórica, deparou-se com incipiente produção científica acerca da compreensão de familiares sobre cuidados paliativos.

\section{Câncer e cuidados paliativos}

À medida que cresce em estatísticas, é comum se ouvir falar de câncer como doença incurável, e, diante do diagnóstico, mesmo havendo recursos terapêuticos, em se tratando do câncer, a antecipação da morte é experimentada pelas pessoas ${ }^{10}$.

Quanto ao risco de desenvolvimento, o tabagismo é, ainda, sua principal causa ${ }^{1}$. A detecção da doença em estágio inicial é um desafio, considerando, para tanto, a busca postergada por tratamento e as dificuldades de acesso aos serviços de saúde².

Apesar dos avanços, a toxicidade dos radioterápicos e quimioterápicos no tratamento do câncer é fator preponderante. Isso porque tais terapêuticas podem atingir órgãos e tecidos outros que não somente os que são alvo do tratamento ${ }^{11,12}$. Assim, justifica-se que o cuidado de patologias ameaçadoras da vida deve privilegiar uma abordagem que considere, além dos aspectos físicos, o bemestar global da pessoa adoecida ${ }^{13}$.

Nessa perspectiva, surgiu o movimento hospice, na segunda metade do século $X X$, apostando na efetividade do cuidar ${ }^{4}$. O termo hospice vem do latim e significa hospedaria, seus primeiros registros remontam ao século V. Nesses locais, religiosos, em especial, exerciam a prática do cuidado com viajantes e peregrinos.

Posteriormente, essa prática foi modificada, abrangendo o cuidado a doentes cuja patologia não tem cura $^{14}$. A expansão do movimento hospice pelo mundo tem sua história marcada pela médica inglesa Cicely Saunders. Após a experiência com pacientes fora da possibilidade de cura, Saunders fundou em Londres, em 1967, o Saint Christopher Hospice, cujo modelo inspirou o surgimento de outros ${ }^{4,15}$.

Saunders propôs o termo "dor total" para designar que o sofrimento físico é apenas uma das dimensões afetadas pelo adoecimento, e que o cuidado prestado às doenças que ameaçam a continuidade da vida deve englobar também as dimensões psicológica, social e espiritual. 
Desse modo, na impossibilidade de traduzir adequadamente o termo hospice, a Organização Mundial da Saúde (OMS) adotou a expressão cuidado paliativo. Tal expressão, já utilizada no Canadá, é definida como

[...] abordagem que promove a qualidade de vida de pacientes e seus familiares, que enfrentam doenças que ameacem a continuidade da vida, por meio da prevenção e do alivio do sofrimento. Requer identificação precoce, avaliação e tratamento da dor e outros problemas de natureza biofísica, psicossocial e espiritual ${ }^{16}$. (p. 26)

Diante dessa definição, Arantes ${ }^{17}$ observa que a abordagem desses cuidados deveria se estender a todos os pacientes com doenças graves, progressivas e que ameacem a continuidade da vida.

O trabalho em cuidados paliativos requer uma equipe multiprofissional, composta, no mínimo, por: médico, enfermeiro, psicólogo e assistente social. A depender da necessidade e da realidade, outros profissionais podem ser chamados a integrá-la $a^{3,14}$.

Uma vez abordado o tema cuidados paliativos, é interessante traçar algumas linhas sobre a noção de família e a importância da comunicação em cuidados paliativos.

\section{Família, adoecimento e comunicação em cuidados paliativos}

A noção de família, segundo a visão sistêmica, abrange um complexo de relações em interação e transformação constantes. Daí não ser possível uma definição que abarque a diversidade de arranjos familiares ${ }^{18}$.

Nesse sentido, Franco defende que a "família pode ser entendida como um sistema no qual a soma das partes é mais do que o todo"7 (p. 358), acrescentando que aquilo que afeta o sistema afetará cada indivíduo. Para a autora, ao se depararem com acontecimentos que ameaçam o funcionamento desse sistema, esses indivíduos tentam restaurar o seu equilíbrio, seja por meio de seus papéis, padrões de enfrentamento ou regras de comunicação.

A antecipação da perda e a morte iminente concorrem para a desorganização do equilíbrio familiar. Diante disso, a hospitalização torna-se mais um desafio a ser enfrentado, especialmente por despertar o conflito entre a vida e morte ${ }^{19,20}$. Nesse contexto, a comunicação é pedra angular, no sentido de favorecer ou dificultar a relação da equipe de saúde com a família.

Kovács ${ }^{8}$ lembra quão importante é a questão da comunicação nas situações de cuidados paliativos. Para a autora, uma comunicação efetiva, harmoniosa e centrada nas necessidades do doente pode produzir contribuições valiosas para o controle de desconfortos físicos, minimizando o sofrimento de pacientes e familiares.

Essa comunicação passa, também, pelo ato de escutar, estar atento ao que é dito e ao modo como é dito, incluindo expressões faciais, gestos e sentimentos. Isso se torna desafiador quando não se lhe reserva um tempo necessário. Não se trata, portanto, do simples ato de informar, mas de ser presença empática na dor do outro ${ }^{21}$.

Caponero e Vieira ${ }^{22}$ definem comunicação como uma habilidade capaz de minimizar a ansiedade de pacientes e familiares por meio da oferta de informações e explicações adequadas. Comunicarse adequadamente é uma aptidão que pode ser desenvolvida e aperfeiçoada, bastando, para tanto, dispor do tempo para ouvir e permitir que o diálogo ocorra.

Rosemberg ${ }^{23}$ acrescenta que o profissional de saúde já comunica alguma mensagem por meio de sua presença, mesmo que não intencione, pois a fala não é meio exclusivo de transmissão de mensagens. A entonação de voz, o silêncio e as pausas produzem algum sentido naquele que ouve.

O Conselho Regional de Medicina do Estado de São Paulo ${ }^{6}$ destaca a "excelente comunicação" como fator primordial no enfrentamento da doença por parte dos pacientes e seus familiares. A boa comunicação é atributo necessário à equipe profissional nos cuidados paliativos, por promover o conhecimento e a conscientização de todos os envolvidos no processo.

O referido conselho assegura que, em cuidados paliativos, a ênfase deve ser atribuída à qualidade das relações. Considerando a doença em fase avançada, é imprescindível a comunicação honesta e completa. 
A Política Nacional de Humanização (PNH), lançada em 2003, faz referência à comunicação como ferramenta no enfrentamento das relações de poder, trabalho e afeto. A ênfase à comunicação consiste nas mudanças possíveis de relacionamentos entre os atores que compõem o cenário da saúde: trabalhadores, usuários e gestores ${ }^{24}$.

Para Deslandes et al. ${ }^{25}$, os princípios da $\mathrm{PNH}$ estabelecem relação estreita com as proposições de Habermas acerca do agir comunicativo. Segundo essa proposta, a ação comunicativa possibilita o entendimento por meio do diálogo. O que não significa, simplesmente, emitir ou compreender um conteúdo, mas, sim, conceber novas versões de mundo, sofrimento e cuidado.

Nesse sentido, uma ação comunicativa abre espaço para a troca e considera o conhecimento do outro como válido. Independentemente da posição que ocupa no diálogo, suas proposições são aceitas, pois traduzem conhecimentos técnicos e vivenciais distintos ${ }^{25}$.

Desse modo, buscar a compreensão de familiares sobre os cuidados paliativos é considerar que seus referentes sobre esse termo carregam elementos do contexto no qual compartilham a vivência da doença, especialmente no tocante à comunicação que circula nesse espaço.

\section{Métodos e técnicas}

Desenvolveu-se uma pesquisa qualitativa de cunho exploratório. Segundo Minayo ${ }^{26}$, o estudo qualitativo melhor se aplica a "situações particulares, grupos específicos e universos simbólicos" (p. 76). Por sua vez, a pesquisa exploratória permite considerar aspectos variados no tocante ao fato estudado, por possuir planejamento flexível ${ }^{27}$.

O estudo foi realizado em um hospital terciário localizado na cidade de Fortaleza-CE, especializado no diagnóstico e tratamento de patologias cardíacas e pulmonares. É também referência, no NorteNordeste, na realização de transplantes de coração e pulmão.

Os dados foram coletados entre agosto e outubro/2015 em uma unidade de pneumologia que dispõe de 30 leitos destinados à internação de pacientes em tratamento clínico, investigação diagnóstica e cirurgias. Do total de leitos, dois são apartamentos, destinados aos pacientes póstransplantados de pulmão.

Essa unidade conta com uma equipe multiprofissional composta por: médicos, enfermeiros, técnicos e auxiliares de enfermagem, fisioterapeutas, nutricionista, psicólogo, assistente social e terapeuta ocupacional. Oriundos dessa mesma equipe, profissionais das categorias enfermagem, medicina, psicologia, terapia ocupacional e serviço social compõem a equipe de cuidados paliativos da unidade pesquisada.

O critério para que o paciente seja atendido nessa perspectiva é definido pela avaliação clínica, que inclui, como protocolo, uma escala desenvolvida no Canadá e traduzida, preliminarmente, pela Academia Nacional de Cuidados Paliativos, a Palliative Performance Scale (PPS). Essa escala inclui na avaliação: a capacidade de deambulação (caminhar), nível de comprometimento pela doença em atividades laborais, autocuidado, ingestão alimentar e nível de consciência ${ }^{3}$.

Foi critério de inclusão na pesquisa: ser familiar e estar acompanhando o paciente, ter mais de 18 nos, e ter conhecimento do diagnóstico de câncer desse paciente. Como critério de exclusão, elegeu-se ser familiar de pacientes com diagnósticos de outras doenças pulmonares.

A seleção dos entrevistados se deu por conveniência. Solicitou-se à equipe da unidade que indicasse os pacientes sob os cuidados paliativos. O número de participantes, no caso 15 familiares, foi definido pelo critério de saturação das respostas. Os dados do diagnóstico foram obtidos nos prontuários.

Para a coleta de dados, realizou-se entrevista semiestruturada, gravada, destruindo-se as mídias após transcrição dos dados. As perguntas norteadoras, elaboradas pelas pesquisadoras, foram: 1) 0 que você conhece da doença do seu familiar? 2) Como você acha que é tratado o câncer? 3) O que você espera do tratamento que vem sendo realizado? 4) Como você entende a questão da cura no caso do câncer? 5) Cuidados paliativos, você já ouviu falar ou sabe o que é? Além dessas perguntas, coletou-se, também, idade, sexo, grau de parentesco e escolaridade dos entrevistados. 
Para tratamento dos dados, utilizou-se a Análise de Conteúdo, por se tratar de um conjunto de técnicas aplicadas à análise de discursos diversos, possibilitando, ao pesquisador, a compreensão e descrição dos conteúdos das mensagens ${ }^{28}$.

Dentre as funções desse método, a função heurística enriquece a tentativa exploratória e aumenta a propensão à descoberta; já a função de 'administração da prova' parte da elaboração de hipóteses como tentativa de afirmar ou não as questões propostas.

Após análise e compreensão do material coletado, as falas foram organizadas em unidades de registros, permitindo a eleição de categorias. No decorrer da discussão, essas falas serão indicadas pela sigla FC (familiar cuidador), seguidas do número correspondente de participação, assim aparecerão de FC1 a FC11.

Em respeito aos aspectos éticos e legais, a pesquisa atendeu às recomendações da Resolução do Conselho Nacional de Saúde (CNS) no 466, de 12 de dezembro de $2012^{29}$. O projeto foi submetido ao Comitê de Ética em Pesquisa do hospital pesquisado e obteve aprovação.

\section{Resultados e discussão}

Dos 15 entrevistados, 11 atenderam aos critérios de inclusão, compondo a amostra final. Desse total, nove eram mulheres e dois homens. A idade variou entre 18 e 59 anos. Referente ao grau de escolaridade, três tinham Ensino Fundamental (in)completo, sete com Ensino Médio (in)completo, e um com ensino técnico. Quanto ao parentesco, prevaleceram os filhos (as), no total de oito; os demais foram dois esposos (as) e um sobrinho (a).

No tocante ao estádio da doença, todos os pacientes dos familiares entrevistados estavam no estádio IV, onde o câncer já compromete mais de um órgão e o tratamento ofertado é paliativo².

Da leitura do material coletado surgiram duas categorias: a primeira, 'Compreensão da doença' e, a segunda, 'O saber não saber: sentidos de cuidados paliativos'. Dessa última emergiu a subcategoria "do desconhecimento do termo à construção de sentidos". Finalizando a discussão dessas categorias, aborda-se a repercussão da comunicação equipe-família na construção dos sentidos de cuidados paliativos.

\section{Compreensão da doença}

Essa categoria é representativa dos elementos que se destacaram na compreensão do câncer, tratamento e cura. Apesar de os entrevistados referirem conhecimento do quadro clínico de seus familiares, suas falas refletem elementos que sugerem desconhecimento acerca da doença ou, ainda, não terem sido devidamente informados sobre o câncer, como se evidencia a seguir:

\footnotetext{
“Do que conheço é só o que ela tem, esse câncer, primeiramente ela veio com negócio de cansaço, aí aqui nós descobrimos esse câncer". (FC2)
}

“Eu particularmente não tenho muita informação sobre o câncer não. Só sei que é um câncer e sei também que não é uma coisa muito boa". (FC5)

“Eu entendo muito pouco e eu sei muito pouco. Só sei que é CA no pulmão, que é muito grave, que ela tá (sic) numa fase muito avançada, e já tá nos dois pulmões, pouca coisa que eu sei". (FC1)

A esse respeito, $\operatorname{Tesser}^{30}$ entende que a construção da verdade e o seu uso pelo médico está relacionada com a missão social de curadores que os profissionais médicos recebem. Aos leigos apenas cabe confiar nessa verdade. 
O câncer revela a imagética da morte por meio dos sentidos de destruição. Aquilo que é estranho e sequer deve ser pronunciado torna-se também familiar, no sentido de ser socialmente compartilhado. A ideia de aniquilamento diante de um inimigo cujo arsenal é desconhecido ${ }^{31}$ atravessa a compreensão da doença.

"Olha, pra mim, é como se fosse um... você joga uma pedra em um bicho que é feroz, né, ele sai correndo atrás de você, tentando te destruir, tentando te matar, sabe assim. É isso que tá... eu acho, que tá acontecendo com a minha mãe, essa coisa, que eu não quero nem dizer o nome, destruindo ela, destruindo a respiração dela [chora copiosamente]". (FC3)

Esses achados corroboram a literatura sobre a crise que se instala na família diante de doenças que ameaçam a continuidade da vida, revelando a antecipação da perda e a morte iminente como concorrentes da desorganização do equilíbrio familiar, ${ }^{7,19}$.

No tocante ao tratamento da doença, todos os participantes demonstram conhecimento da terapêutica, citando a radioterapia e/ou a quimioterapia, mas os efeitos indesejáveis foram destacados pela maioria dos participantes, que referiram piora no quadro clínico como reação ao tratamento.

As reações adversas desses tratamentos incluem: cansaço, enjoo, vômitos, fraqueza, perda de apetite, alterações no peso, feridas na boca, entre outras. Os efeitos indesejáveis se estendem à dinâmica familiar, podendo causar mais sofrimento, além do produzido pelo diagnóstico em si si1,12,32 $^{\text {. }}$.

No que se refere à noção de cura, os participantes ressaltam a fé como recurso de enfrentamento da doença, mesmo reconhecendo a impossibilidade de cura pelo tratamento ofertado.

É relevante citar que a dimensão espiritual integra os princípios dos cuidados paliativos, implicando o reconhecimento de que, diante das doenças ameaçadoras da vida, o suporte espiritual pode propiciar a ressignificação dessa vida, do sofrimento do paciente, da sua dor e morte ${ }^{11}$.

\section{O saber não saber: sentidos de cuidados paliativos}

Essa categoria revela o movimento dos participantes na construção dos sentidos de cuidados paliativos. O saber não saber faz referência ao fato de que ainda que desconhecido para a maioria dos participantes, as tentativas de tradução do termo são alusivas ao que, de fato, constitui a filosofia desses cuidados.

\section{Do desconhecimento do termo à construção de sentidos}

Ainda que demonstrando conhecer o diagnóstico e o prognóstico de seu paciente, alguns familiares não conseguiram atribuir sentido ao termo cuidados paliativos. Quando abordados sobre a questão, apresentaram falas que revelam desconhecimento desses cuidados.

"Como assim? Não senhora, não, não. Nem tenho ideia do que seja. Cuidado com a doença é? Pois sim? Mas como assim? Ela não é contagiosa não, né? Ou é?" (FC4)

"Não, se o médico falou eu não lembro". (FC1)

"A minha filha tinha falado e eu ouvi ontem, né, mas não lembro não". (FC10)

Em outra fala, cuidado paliativo foi 'confundido' com 'cuidado avaliativo': “Não, assim, uma avaliação, né? Você tá ali olhando ela, ela tá melhorando, piorando, pronto. É uma avaliação que a gente tá tendo do paciente, entendeu?" (FC6).

Aproximando-se o termo do vocábulo 'avaliar' no contexto dos cuidados paliativos percebe-se que, na prática, esses cuidados são também avaliativos, no sentido de avaliação de sintomas, que são tanto físicos quanto psicológicos, sociais e espirituais. Porém, ao ser esclarecido acerca do que efetivamente Ihe foi perguntado, o participante considera o termo 'paliativo' como novo, desconhecido. 
“Não, não, nunca escutei falar. Mas eu creio que tenha a ver com avaliativo. É desconhecida, né, essa palavra, PA-LI-A-TI-VO [soletra]? É uma coisa nova e pouco divulgada, né? Porque se chegasse aqui e dissesse "vai ganhar mil reais pra me explicar o que é paliativo" eu tinha perdido esses mil reais". (FC6)

A esse respeito, Pimenta e Mota ${ }^{33}$ concluem que, embora o alívio de sintomas seja tão antigo quanto a história do cuidado, o ressurgimento da ênfase no alívio da dor e na prática dos cuidados paliativos é recente, sendo reduzido o número de profissionais que a conhecem. Por sua vez, Figueiredo ${ }^{15}$ observa que, além de novo na área da saúde, o cuidado paliativo não é bem aceito, seja pela comunidade científica ou leiga.

Diante disso, acredita-se que a dificuldade da equipe de comunicar adequadamente o significado do termo cuidado paliativo para os familiares deriva do fato de que se trata de novidade também para os profissionais, que devem, primeiro, incorporá-lo ao seu conhecimento.

Concebe-se, ainda, para os cuidados paliativos, o sentido de 'cuidado diferenciado'. Tal concepção parece estar vinculada ao reconhecimento de que conforme a doença progride e as chances de cura diminuem, faz-se necessário o cuidado dos sintomas indesejáveis ${ }^{14}$.

"Como? Não. Tipo assim, como que fosse eu filha dela cuidasse dela? Eu acho que é isso. [E esse cuidado é só a família que pode oferecer?] Só não! Os amigos...e os médicos. Ele é um cuidado diferenciado, agora eu só não sei. Cuidado eu sei, mas paliativo não". (FC8)

“Não sei o que é. Se for o que eu faço, né? Porque eu cuido dela, tô (sic) aqui dia e noite, banho ela, dou alimentação dela, dou remédio, fico observando ela, pelo que eu sei só se for isso". (FC2)

“Eu já escutei, mas não sei te definir... cuidados que deve ter com o paciente? Até porque quem tá doente precisa de um cuidado maior, do que qualquer ser humano, né? Todos nós temos nossos limites, mas quem tá doente tá mais debilitado né? Precisa de mais cuidado". (FC9)

Assemelhar o cuidado realizado aos cuidados paliativos adquire, nas falas anteriores, um sentido de cuidar na essência, sem, no entanto, se nomear que tipo de cuidado é esse. Para Volich, "cuidar pressupõe colocar-se ao do lado do sujeito, inclinando-se à sua dor" ${ }^{34}$ (p. 82). E o que têm feito esses familiares, senão cuidar de seus doentes?

Igualmente, essa aproximação lembra que, na abordagem paliativa, cuida-se essencialmente dos sintomas para minimizar o sofrimento. Cuidar, portanto, não pressupõe salvar, tampouco abandonar, mas acompanhar, quando a cura não é o foco da atenção ${ }^{4,35}$, como referido por este familiar:

"Aqui eu ouvi falar. Assim, paliativo eu acho que é as medicações, não sei se é isso, né? A medicação, a medicação dela que eles estão dando pra..., assim, ajudar a ela a... assim, respirar melhor, entendeu? É, assim no meu ver, é isso, né? Eles estão cuidando, os médicos estão cuidando dela no que possível, da maneira deles, né?" (FC3)

$\mathrm{Na}$ fala a seguir, a expressão cuidados paliativos adquire o sentido de uma terapêutica que visa minimizar o sofrimento e propiciar qualidade de vida, embora inclua outros elementos:

“É um tratamento que ele vai dando mais qualidade de vida. A pessoa vai...não é assim como a quimioterapia em si, ele [cuidado paliativo] vai...é um tratamento que a pessoa vai sentir menos, pra ela não sofrer tanto. [...] pra ela ter mais uma qualidadezinha de vida [...] ela vai até o dia que Deus quiser [chora]. [...] é só esperar e cuidar bem, dar dignidade, só isso. Não adianta a gente querer forçar, tem que cuidar e cuidar bem!" (FC11) 
Pelo que se pôde observar na fala anterior, à medida que os cuidados paliativos são definidos, a referência à qualidade de vida é posta no diminutivo, do que se pode inferir o sentido de cuidados prestados ao final da vida. Já ao expressar "cuidar bem, dar dignidade", o familiar remete ao que Guimarães ${ }^{4}$ observa ao referir que, independentemente do estágio da doença e dos tratamentos realizados, há sempre algo a ser feito para melhorar a qualidade de vida no tempo que resta.

Ao que parece, esse familiar privilegia o cuidar em detrimento da obstinação terapêutica, ofertando mais qualidade de vida aos dias que restam ao paciente. Kovács ${ }^{13}$ define "obstinação terapêutica" como a tentativa de prolongar a vida a todo custo, mediante o emprego de atitudes que se distanciam da prática dos cuidados paliativos. Para a autora, os cuidados paliativos não apreciam a Eutanásia (apressamento da morte), tampouco a Distanásia (prolongamento da morte com grande sofrimento), mas encaram a morte como processo natural e um componente da vida, privilegiando a chamada morte com dignidade, ou Ortotanásia.

Assim, acredita-se que a compreensão do termo cuidados paliativos pelos familiares é representativa do modo como circulam as mensagens sobre esses cuidados no cenário do estudo. Pelo que foi observado, algumas questões acerca da comunicação equipe/família podem ser elencadas.

Como visto anteriormente, poucos referem conhecer de fato o que são os cuidados paliativos, e os que arriscam fornecer um sentido para o termo o fazem anunciando, previamente, desconhecê-lo. Pode-se inferir dessa circunstância a ausência de um agir comunicativo nesse cenário ${ }^{25}$.

Observa-se ainda que a ausência de uma ação comunicativa pode comprometer o enfrentamento da doença. Basta que se considere a boa comunicação como atributo necessário à promoção do conhecimento e conscientização de todos os envolvidos no cuidado 6 .

Para tanto, Kovács ${ }^{13}$ assegura que, em cuidados paliativos, a postura frente ao tratamento muda de uma posição paternalista para assimétrica. O que significa dizer que, na assimetria, todos os envolvidos (paciente-equipe-família) participam das decisões do tratamento.

Pelos pressupostos da $\mathrm{PNH}^{24}$, acredita-se que a ausência de uma comunicação favorável à compreensão dos cuidados paliativos compromete o enfrentamento das relações de poder. Sobretudo, no que concernem as mudanças propostas quando se abre espaço de discussão aos atores do cenário da saúde.

A partir das falas dos familiares, quando expuseram o estranhamento causado pelo termo cuidado paliativo, pode-se inferir que a comunicação equipe/família parece não favorecer a construção de um sentido para esses cuidados. Isso pode ser fruto da carência de informações técnicas fornecidas a esses familiares ${ }^{20}$.

A inferência sobre a carência de informações técnicas no contexto da pesquisa tem por base o fato de que, apesar de os pacientes dos familiares entrevistados estarem em cuidados paliativos, à maioria referiu desconhecer o termo.

A esse respeito, Kovács ${ }^{36}$ sugere o desenvolvimento da comunicação, por parte das equipes, como prioridade dos programas de cuidados paliativos. A autora defende que, além de funcionar como mediadora da relação equipe/paciente/família, a comunicação tem por finalidade promover a dignidade. 
Ademais, o profissional de saúde se situa nas esferas do conhecimento técnico e vivencial, o que o faz responsável pela transmissão de conceitos e ideias, dado o lugar que ocupa. Sua presença e suas práticas na sociedade são transmissoras de mensagens, tenha ele intenção ou não de comunicar ${ }^{23}$.

Acredita-se, também, no desenvolvimento da comunicação adequada como habilidade a ser aperfeiçoada, desde que reconhecida como necessária à prática dos cuidados paliativos ${ }^{22}$. Afinal, em uma abordagem onde a cura não é foco, mas, sim, o cuidado, comunicar está para além do ato de informar, significa ser presença na dor do outro ${ }^{21}$.

Diante do que foi exposto, pode-se inferir que os cuidados paliativos são pouco compreendidos e não são nomeados pelos familiares. Além disto, sua nomenclatura causou estranhamento a parte considerável dos participantes. Percebeu-se, ainda, que o desconhecimento do termo é atravessado pela comunicação que parece não favorecer o entendimento dessa terapêutica no espaço da pesquisa.

\section{Considerações finais}

Pretendeu-se, com este estudo, alcançar certa compreensão dos sentidos do termo cuidados paliativos, por familiares, no contexto do câncer de pulmão, como, também, discutir a repercussão da comunicação equipe-família nessa construção.

Os resultados mostram que os sentidos atribuídos aos cuidados paliativos surgem de um estranhamento em relação ao termo à aproximação da noção de cuidados com a doença. Poucos dos participantes apresentaram referentes do conceito e da filosofia dessa abordagem.

Não foi possível identificar o que levou alguns participantes a adquirirem essa noção do que são os cuidados paliativos e outros não. No entanto, percebe-se uma falha na comunicação entre equipe e família. De que ordem é essa falha, não foi objeto desta pesquisa investigar, mas sugere-se a realização de estudos futuros que possam buscar a compreensão da equipe sobre os cuidados paliativos.

Buscar a compreensão de cuidados paliativos junto aos familiares talvez tenha sido uma pretensão ousada, uma vez que essa prática é nova até para os profissionais, conforme dados apresentados anteriormente, sendo recente, também, no lócus da pesquisa.

Desse modo, conclui-se que, apesar de os cuidados paliativos serem pouco compreendidos e não nomeados pela maioria dos familiares, os achados apontam que o terreno é fértil para se difundir a filosofia dessa abordagem, uma vez que esses cuidados já são realizados na prática da equipe da unidade pesquisada.

Tais achados contribuem para a intervenção da equipe interprofissional junto aos familiares de pacientes em cuidados paliativos, uma vez que permitem atentar, especialmente, ao modo como a comunicação circula nesse cenário.

Ressalta-se que a pesquisa sinaliza a necessidade de formação e difusão da prática dos cuidados paliativos, sobretudo, no que concerne à comunicação enquanto ferramenta de potencialização do cuidado ao outro. $E$, por fim, promove a contínua reflexão sobre saberes e práticas no contexto da saúde. 


\section{Colaboradores}

Maria Edilania Matos Ferreira Furtado: participou ativamente da elaboração do artigo, de sua discussão, resultados e redação; Darla Moreira Carneiro Leite participou ativamente na orientação da construção e revisão final do texto.

\section{Referências}

1. Ministério da Saúde (BR). Instituto Nacional do Câncer José Alencar Gomes da Silva. Coordenação de Prevenção e Vigilância. Estimativa 2016: incidência de câncer no Brasil. Rio de Janeiro: INCA; 2015.

2. Gampel O. Câncer de pulmão. In: Kovacs MJ, Franco MHP, Carvalho VA, organizadores. Temas em psico-oncologia. São Paulo: Summus; 2008. p. 130-3.

3. Academia Nacional de Cuidados Paliativos. Manual de cuidados paliativos. Rio de Janeiro: Diagraphic; 2012.

4. Guimarães RM. Filosofia dos cuidados paliativos. In: Saltez E, Juver J, organizadores. Cuidados paliativos em oncologia. Rio de Janeiro: Ed. Senac Rio de Janeiro; 2014. p. $13-23$

5. Pessini L. Bioética e cuidados paliativos: alguns desafios do cotidiano aos grandes dilemas. In: Pimenta CAM, Mota DDCF, Cruz DALM, organizadores. Dor e cuidados paliativos: Enfermagem, Medicina e Psicologia. Barueri, SP: Manole; 2006. p. 45-66.

6. Conselho Regional de Medicina do Estado de São Paulo. Cuidado paliativo. São Paulo: Cremesp; 2008

7. Franco MHP. A família em psico-oncologia. In: Kovacs MJ, Franco MHP, Carvalho VA, organizadores. Temas em psico-oncologia. São Paulo: Summus; 2008. p. 358-61.

8. Kovács MJ. Comunicação em cuidados paliativos. In: Pimenta CAM, Mota DDCF, Cruz DALM, organizadores. Dor e cuidados paliativos: enfermagem, medicina e psicologia. Barueri, SP: Manole; 2006. p. 86-102.

9. Ministério da Saúde (BR). Departamento de Informática do SUS. Sistema de Informações sobre Mortalidade (SIM) [Internet]. 2012 [citado 20 Maio 2016]. Disponível em: http://tabnet.datasus.gov.br/cgi/tabcgi.exe?idb2012/c04.def

10. Ribeiro EMPC. O paciente terminal e família. In: Carvalho MMMJ, coordenador. Introdução à psiconcologia. Campinas: Livro Pleno; 2003. p. 197-218.

11. Fitch $M$. Necessidades emocionais de pacientes e cuidadores em cuidados paliativos. In: Pimenta CAM, Mota DDCF, Cruz DALM, organizadores. Dor e cuidados paliativos: enfermagem, medicina e psicologia. Barueri: Manole; 2006. p. 67-85.

12. França BAL. O tratamento do paciente com câncer. In: Angerami-Camon VA, Gaspar KC, organizadores. Psicologia e câncer. São Paulo: Casa do Psicólogo; 2013. p. 117-38.

13. Kovács MJ. Comunicação nos programas de cuidados paliativos: uma abordagem multidisciplinar. In: Pessini L, Bertachini L, organizadores. Humanização e cuidados paliativos. São Paulo: Loyola; 2004. p. 275-86.

14. Doyle D. Bilhete de plataforma: vivências em cuidados paliativos. Tradução de Figueiredo MTA, Figueiredo MGMCA. Rio de Janeiro: Senac Rio; 2012.

15. Figueiredo MGMCA. Cuidados paliativos. In: Kovacs, MJ, Franco MHP, Carvalho VA, organizadores. Temas em psico-oncologia. São Paulo: Summus; 2008. p.382-7.

16. Matsumoto DY. Cuidados paliativos: conceitos, fundamentos e princípios. In: Carvalho RT, Parsons HA, organizadores. Manual de cuidados paliativos da ANCP. Rio de Janeiro: Diagraphic; 2012. p. 23-30. 
17. Arantes ACLQ. Indicações de cuidados paliativos. In: Carvalho RT, Parsons HA, organizadores. Manual de cuidados paliativos da ANCP. Rio de Janeiro: Diagraphic; 2012. p. 56-74.

18. Böing E, Crepaldi MA, Moré CLOO. Pesquisa com famílias: aspectos teóricometodológicos. Paidéia: 2008; 18(40):251-66.

19. Rolland JS. Ajudando famílias com perdas antecipadas. In: Walsh F, Mcgoldrick FM, organizadores. Morte na família: sobrevivendo às perdas. Porto Alegre: Artes Médicas; 1998. p. 166-85.

20. Oliveira EBS, Sommermam RDG. Família hospitalizada. In: Romano BW, organizador. Manual de psicologia clínica para hospitais. São Paulo: Casa do Psicólogo; 2012. p. 117-44.

21. Pessini L, Bertachini L. Novas perspectivas em cuidados paliativos: ética, geriatria, gerontologia, comunicação e espiritualidade. O Mundo da Saúde. 2005; 29(4):491-509.

22. Caponero R, Vieira DE. Urgências em cuidados paliativos. In: Pimenta CAM, Mota DDCF, Cruz DALM, organizadores. Dor e cuidados paliativos: enfermagem, medicina e psicologia. Barueri: Manole; 2006. p. 301-16.

23. Rosemberg B. Comunicação e participação em saúde. In: Campos GWS, Minayo MCS, Akerman M, Drumond Junior M, Carvalho YM, organizadores. Tratado de saúde coletiva. São Paulo: Hucitec; 2012. p. 795-826.

24. Ministério da Saúde (BR). Humaniza SUS: Política Nacional de Humanização. Brasília: MS; 2004.

25. Deslandes SF, Mitre RMA. Processo comunicativo e humanização em saúde. Interface (Botucatu) [Internet]. 2009 [citado 12 Jan 2012]; 13(supl 1):641-9. Disponível em: http://www.scielo.br/pdf/icse/v13s1/a15v13s1

26. Minayo MCS. O desafio do conhecimento: pesquisa qualitativa em saúde. São Paulo: Hucitec; 2014.

27. Gil AC. Como elaborar projetos de pesquisa. São Paulo: Atlas; 2008.

28. Bardin L. Análise de conteúdo. Lisboa: Edições 70; 2011.

29. Ministério da Saúde (BR). Conselho Nacional de Saúde. Resolução nº 466, de 12 de dezembro de 2012. Aprova diretrizes e normas regulamentadoras de pesquisa envolvendo seres humanos [Internet]. Brasília, DF: CNS; 2012 [citado 20 Abr 2016]. Disponível em: http://conselho.saude.gov.br/resolucoes/2012/Reso 466.pdf

30. Tesser CD. A verdade na biomedicina, reações adversas e efeitos colaterais: uma reflexão introdutória. Physis: Rev Saude Colet. 2007; 17(3):465-84.

31. Angerami-Camon VA, Gaspar KC. A subjetivação do câncer. In: Angerami-Camon VA, Gaspar KC, organizadores. Psicologia e câncer. São Paulo: Casa do Psicólogo; 2013. p. 56-74.

32. David A, Windlin I, Gaspar KC. O paciente oncológico e a terapêutica quimioterápica: uma contribuição da psicologia. In: Angerami-Camon VA, Gaspar KC, organizadores. Psicologia e câncer. São Paulo: Casa do Psicólogo; 2013. p. 295-311.

33. Pimenta CAM, Mota DDCF. Educação em cuidados paliativos: componentes essenciais. In: Pimenta CAM, Mota DDCF, Cruz DALM, organizadores. Dor e cuidados paliativos: enfermagem, medicina e psicologia. Barueri: Manole; 2006. p. 9-44.

34. Volich RM. O cuidar e o sonhar. Por uma outra visão da ação terapêutica e do ato educativo. In: Pessini L, Bertachini L, organizadores. Humanização e cuidados paliativos. São Paulo: Loyola; 2004. p. 71-85. 
35. Silva MJP. Comunicação com pacientes fora de possibilidades terapêuticas: reflexões. In: Pessini L, Bertachini L, organizadores. Humanização e cuidados paliativos. São Paulo: Loyola; 2004. p. 263-72.

36. Kovács MJ. Aproximação da morte. In: Kovacs MJ, Franco MHP, Carvalho VA, organizadores. Temas em psico-oncologia. São Paulo: Summus; 2008. p. 388-97.

Furtado MEMF, Leite DMC. Cuidados paliativos desde la óptica de familiares de pacientes con neoplasia de pulmón. Interface (Botucatu). 2017; 21(63):969-80.

Los cuidados paliativos defienden el empleo de terapéuticas de alivio del sufrimiento de pacientes con enfermedades que amenazan la vida, respetando sus dimensiones física, síquica, social y espiritual. En este sentido, se buscó captar lo que los familiares de pacientes con neoplasia de pulmón entienden por esa terapéutica. Se trata de un estudio cualitativo de cuño exploratorio, en el cual se realizaron 11 entrevistas semiestructuradas con familiares cuidadores. Los datos obtenidos se sometieron al análisis de contenido y fueron articulados con la literatura sobre cuidados paliativos. La comprensión de los cuidados paliativos va desde el desconocimiento del término hasta la noción de cuidados con la enfermedad. Se concluyó que la comunicación equipo-familia es esencial en la construcción de esa comprensión y que, incluso no habiendo reconocimiento del término por la mayor parte de los familiares, los resultados muestran que el escenario de la encuesta es propicio a la implantación de la filosofía de los cuidados paliativos.

Palabras clave: Cuidados paliativos. Familia. Neoplasias pulmonares. Comunicación. 